\title{
ENTREVISTA COM ARTUR CruzeIRo SeIXAS
}

http://dx.doi.org/10.11606/issn.2175-3180.v13i24p13-20*

Por Ana Cristina Joaquim ${ }^{\mathrm{I}}$

A entrevista que se segue foi realizada em outubro de $2013 \mathrm{em}$ dois momentos distintos: primeiramente, enviei por e-mail as questões a Cruzeiro Seixas (que à época estava às vésperas de completar 93 anos), às quais ele respondeu pela mesma via de maneira sucinta, devido a sua dificuldade de visão. Num segundo momento, fiz uma visita a sua residência em Vila Nova de Famalicão, onde gravamos a conversa, de modo que as questões puderam ser mais desenvolvidas. O resultado que aqui se apresenta é, portanto, uma mescla das suas respostas escritas com trechos de maior interesse transcritos a partir desse encontro presencial. Registro aqui a minha gratidão pela hospitalidade e generosidade com que fui recebida, e a imensa admiração pelo trabalho criativo e coerência ética deste grande expoente do surrealismo português.

ANA CRISTINA JOAQUIM: Ao olhar para o surrealismo português, noto com bastante evidência algumas características nacionais-identitárias. A experiência de leitura é muito diversa daquela que temos quando lemos qualquer surrealista francês. Para ser ainda mais central na questão, quando leio seus poemas, o que mais me chama atenção é a recorrência com que o mar se faz presente... Tendo isso em vista, o que você diria sobre as maneiras que o surrealismo português teve de se reapropriar da tradição nacional?

\footnotetext{
* Publicada originalmente na revista Desassossego, v. 7, n. 13, jun/2015:

https://www.revistas.usp.br/desassossego/issue/view/7784

DOI original: http://dx.doi.org/10.11606/issn.2175-3180.v7i13p136-141

I Universidade de São Paulo, São Paulo, Brasil.
} 
ARTUR CRUZEIRO SEIXAS: Serei eu um caso especial? Foi lento o meu conhecimento em profundidade do Surrealismo Francês. Cesariny e os outros amigos não trabalhavam como eu que, por isso, dispus de pouco tempo para leituras. Eu não sou nem um intelectual, nem um artista, essas duas palavras, as recebo como uma bofetada. Sou um homem entre os homens, nada além. O homem comum deveria ter paixão pelas coisas, e, no entanto, no máximo, tem paixão pelo dinheiro. Em 1950, embarquei como tripulante de um navio cargueiro e aí andei por cerca de 2 anos. $\mathrm{O}$ mar já estava, por certo, dentro de mim pelas navegações históricas (as referências todas que carrega um português), de modo que a presença do mar nos meus escritos nunca foi uma atitude pensada, como não o foram outros elementos da minha poesia, que sempre foi feita do próprio acaso, sem premeditação. As pessoas são intuitivas ou não são, de modo que há pessoas fantásticas capazes de absorver determinados elementos do mundo e devolver-nos em forma de criação ou pulsão surrealista; acredito que a condição social apenas em parte é responsável pelo que alguém é capaz de fazer em vida. Ainda quanto ao mar, eu diria que é quotidiano e dele é uma grande parte de nós.

ACJ: Ainda pensando nas peculiaridades do surrealismo em Portugal, surge essa variação intitulada abjeccionismo, tal como teria proposto Pedro Oom, que gerou inclusive a publicação de uma antologia organizada pelo Cesariny. Esse conceito, pelo que pude entender, tem duas frentes de diferenciação em relação às ideias de Breton: a primeira delas seria de viés epistemológico e afirma a perpétua renovação das antinomias (enquanto para Breton, persistiria a crença na possível dissolução destas); e a outra seria uma espécie de adequação histórica, no sentido de que a abjecção seria a condição de baixeza moral à qual estaria submetido Portugal sob a ditadura salazarista. Essa segunda frente é assim expressa por António José Forte: “O que pode fazer um homem desesperado quando o ar é um vómito e nós seres abjectos?". No vídeo "Surrealismo abrangente", você manifesta a sua discordância diante desta postura abjeccionista, justificada com a seguinte citação de Cesariny: "pra frente puxam os bois, pra cima puxam os homens". Você poderia desenvolver essa imagem? 
ACS: Quanto ao abjeccionismo, temo definir-me em relação a ele, já que me parece por demais ligado ao tempo ditatorial que então se vivia.

ACJ: Em 2007, houve uma exposição da sua obra em Almonte (Espanha) intitulada "Inventário", em que você homenageou o Herberto Helder. Consultei o catálogo, mas não pude perceber a presença de Herberto Helder nas informações que nele encontrei, de modo que suponho a homenagem como referência à relação de mútua admiração que vocês mantiveram ao longo dos vários anos da atuação de ambos. Você poderia falar um pouco sobre essa relação?

ACS: O Herberto Helder é senhor de uma representatividade que não posso ignorar. Dedicou-me poemas que me parecem sinais de encontro no grande espaço do Surrealismo e, nesse espaço, se notava toda a sua poesia, a meu ver. Conheci-o em África, já com sua barba, estava ele na tropa, coitado, a cumprir uma obrigação como muitos outros soldados. Encontrávamo-nos vez ou outra em cafés, conversávamos sobre a situação política e outras coisas, mas esse foi todo o meu contato com ele, três ou quatro vezes apenas. Quanto a sua poesia, é uma torrente cheia de força, de tal modo que, por vezes, chega a ser ilegível; nele a palavra vai como uma inundação que não olha casas ou ruas, é uma coisa de uma força extraordinária. É uma pena que ele tenha se metido dentro de sua concha... eu penso que nunca estamos fora demais, estamos sempre fora de menos, é preciso sair de si.

ACJ: Em 1928, André Breton se manifesta de maneira escancaradamente homofóbica: "Acuso os pederastas por proporem à tolerância humana um déficit mental e moral que tende a erigir-se em sistema e a paralisar todas as atividades que respeito" ${ }^{1}{ }^{1} \mathrm{O}$ surrealismo em Portugal, diversamente, é pleno de manifestações homossexuais, como posso notar em alguns de seus versos e também em alguns versos de Cesariny. Isso me parece um ganho ético (até mesmo moral...) por parte surrealismo português em

\footnotetext{
${ }^{1}$ Tradução minha de trecho disponível em: http://www.louisaragonelsatriolet.org/spip.php?article23 e, do espanhol:

http://books.google.pt/books?id=XxJDzU_jhFcC\&pg=PA235\&lpg=PA235\&dq=sobre+a+homofob ia +de+Breton\&source=bl\&ots=qif_GvBsEE\&sig=emqlMFSCcltnDg1yjoQs_zIxikI\&hl=en\&sa=X\& ei $=$ XL9mUoyIDMKP7Aac94HIDg\&redir_esc $=y \# v=$ onepage\&q=sobre $\% 20 a \% 20$ homofobia $\% 20 \mathrm{de} \% 20$ Breton\&f= false, p. 235 .
} 
relação ao surrealismo francês, especialmente se levarmos em conta que estes versos circulavam num período de grande repressão de conduta, tal qual foi o salazarismo... Essa manifestação por parte de vocês, acaso pode ser considerada uma militância consciente em favor da causa homossexual? Com essa pergunta eu quero saber se havia essa preocupação, bem como a consciência de que este era um tema um tanto mal resolvido entre os surrealistas franceses.

ACS: Não há jamais em mim "causa homossexual". A homossexualidade foi para mim sempre forma de liberdade contra a sociedade organizada e por essa via um apuramento da sensibilidade e da consciência. Seja na sexualidade dita "normal", seja na homossexualidade, o homem deve sempre procurar a liberdade, que está por toda a parte. Num determinado contexto político em que vivíamos, a homossexualidade era vista como uma soma à postura transgressiva, pois acabava por ser um afrontamento à ordem estabelecida, mas hoje, acredito que já esteja mais "normalizada". Para mim, nunca houve dúvidas de que em qualquer contexto (fosse ele ou não hostil), a homossexualidade seria a minha grande porta para a liberdade, uma das minhas portas, ao menos. O Desnos também era conhecido pela homofobia. Há mil formas de ser homossexual, como há mil formas de não ser. O Cesariny, por exemplo, era completamente diferente de mim na sua maneira de ser. Aliás, ele era um gênio e eu não. Deixou-me uma grandíssima saudade... e, claro, o nosso Rimbaud, que morreu aos 24 anos, o António Maria Lisboa. Ele estaria no mesmo plano de grandeza do Cesariny. Depois houve pessoas interessantíssimas como o Mário Henrique Leiria e o Fernando Alves dos Santos (sobretudo esses dois), que têm obras muito dispersas, de modo que se torna difícil persegui-las. Mas voltando ao tema: a arte como um ato de VIDA (esta palavra que está acima de todas as outras).

$A C J$ : Noto que o corpo, a presença do corpo e a ideia do corpo enquanto fundamento da existência são presenças constantes tanto na sua pintura quanto nos seus versos e, de maneira mais abrangente, aparecem com frequência na criação dos demais autores surrealistas. Eu gosto de ver nessa materialidade corpórea uma resposta surrealista ao racionalismo cartesiano... Você diria que esse foi um empenho de vocês? 
ACS: A alma e a razão só me interessam se forem realmente surrealistas [risos]. Eu não acredito muito nas religiões, elas não me tocam muito. Reconheço a religião como uma característica extraordinária da humanidade, mas não consigo me agarrar a isso. O corpo é meu templo (essa minha devoção pelo corpo...). E, realmente, toda a minha esperança vai para o homem como ele é, com seus defeitos, virtudes e inúmeras possibilidades. São MUITAS as possibilidades para além da razão. É uma pena estarmos num momento da civilização em que não se segue em frente... depois de haver figuras extraordinárias como Freud, que sem dúvida nos ensinou muitíssimo sobre a humanidade, e em seguida o surrealismo que nos abriu portas imensas... Mas as portas todas dão em caminhos tão vastos, que as pessoas ficam tontas e não sabem muito o que fazer com isso.

ACJ: Sobre a sua estadia em África e sobre a importância que um modo de existência não eurocêntrico/ cartesiano deve ter assumido na sua forma de ser surrealista, lemos nessa sua expressão ao fim do livro Viagem sem regresso: "Devo talvez ainda justificar que todos os poemas sejam datados de 'Áfricas'. Isso acontece por identificação moral e física minha com aquele continente, primeiro quando colonizado, agora sofrendo outras tiranias. É com África que completamente me identifico". Eu gostaria que você falasse sobre essa identificação em relação a um povo vítima de tiranias diversas, como você diz.

ACS: Quanto a África e considerando as minhas dificuldades de visão, considero como válido o texto que transcreve do livro "Viagem sem regresso" que me parece guardar ainda a atualidade. Nunca penso num poema como um propósito. Eles tiveram o seu tempo de vida, no meu caso, coincidente com o tempo de África. Na verdade, não sou alguém que viajou procurando itinerários, mas sim alguém que a eles foi obrigado, na maior parte das vezes. Nunca consegui permanecer em Paris mais do que 15 dias - o que era muito pouco para a minha fome de contatos.

ACJ: O Floriano Martins, responsável pela apresentação da publicação brasileira de alguns dos seus poemas², falava, ainda há pouco (22/10/2013), a propósito do surrealismo e das viagens: “(...) Viajar para fora do mundo

2 SEIXAS, Cruzeiro. Homenagem à Realidade. São Paulo: Editora Escrituras, 2005. 
e para dentro do homem. O Surrealismo se torna então um movimento conquistador das distâncias insondáveis, não apenas daquelas imersas na alma humana, mas também a geografia tangível (...). A fatalidade da viagem é que ela não se esgota em suas vertentes, não se limita a seus mapas impressos, nem mesmo nega os limites rascunhados alheios a toda confirmação. As viagens do Surrealismo são antes de tudo a confirmação de uma inquietude (...) O outro lugar sempre foi uma meta do Surrealismo, ponto incomum onde as estranhezas se identificam; terra em que assimilamos as dissonâncias como parte de nossa vida. (...)". Pensei que essa reflexão viria a calhar para pensar na sua atuação, já que - você poderá nos dizer - as viagens foram sempre constitutivas do seu modo de ser surrealista, certo?

ACS: É bom lembrar amigos como Floriano Martins e poder declarar a minha coincidência com o que ele escreveu. Como acabo de dizer, não sou alguém que viajou procurando os seus itinerários, mas minha condição financeira o impunha. Minha poesia foi toda feita em África, depois que pus os pés na Europa não escrevi mais nada. E deu naqueles três livros que a Isabel Meyrelles publicou. Estão ainda por aí, numas pastas, coisas que davam para dois livros pelo menos. Na minha atuação criativa posso com certeza afirmar uma grande liberdade, já que nunca estive a pensar em ganhar dinheiro com ela. Disso advêm consequências, pois estou numa condição péssima, faz-me falta meia dúzia de coisas (não digo uma dúzia) para viver um bocadinho mais intensamente. Gostaria de ir ao Brasil, por exemplo. A minha avó materna era brasileira e falava muito no gerúndio "estou fazendo", "estou dizendo"..., era uma coisa de que eu achava muita graça.

$A C J$ : Sobre os objetos artísticos, fiquei muito sensibilizada em dois momentos de contato com as suas reflexões: ao entrar em sua casa pela primeira vez, você me mostrava paredes e estantes plenas de obras de artistas amigos, de objetos encontrados: a sua coleção afetiva (assim você dizia...). Você apontava: "são meus amigos, meus companheiros". Algumas semanas depois, quando assisti ao documentário "Surrealismo abrangente", registrei algo muito parecido: ao tratar de um quadro do Raúl Perez que se encontra ao abrigo da Fundação Cupertino Miranda, você dizia: "Eu gosto imenso deste. Tenho uma saudade imensa deste quadro". 
Esse seu modo de acompanhar-se da arte é também um modo de personificá-la, de humanizar o objeto artístico...Será este o objetivo maior do surrealismo: um humanismo abrangente? Em que o amor é expandido de modo a suplantar as barreiras mais sólidas que erguemos entre nós e tudo o que nos rodeia?

ACS: Há um problema crucial, de maior importância e é este que eu gostaria que fosse sobretudo notado em nossa conversa: a pintura deve deixar de ser tida como uma coisa que se pendura na parede de um museu e ali permanece. "Ai, que bem que ele pinta o céu", "Ai, que bem que ele pinta nossa ALMA"... A partir de Picasso, de Magritte, de Max Ernst, de toda essa gente, a pintura deixou de ser estética para ser uma ordem social e política, está ali para que os homens se questionem e consigam reelaborar o futuro.

$A C J$ : Ainda sobre as barreiras... Penso que uma das barreiras que mais imperiosamente se coloca é aquela que delimita o espaço do eu, do 'corpo próprio'. O surrealismo de modo geral e o surrealismo português em particular se propuseram romper, de alguma maneira, com essa barreira por meio dos agrupamentos, da criação conjunta, da formação de um coletivo. A despeito das diversas desavenças que marcam a história do surrealismo mundial, eu olho para a sua trajetória e mesmo para a trajetória do Mário Cesariny (e aqui me refiro mais especificamente à trajetória poética) e percebo que ela está marcada fortemente pela imagem do indivíduo, do 'eu', embora haja sempre um 'tu', ainda que um ' $\mathrm{u}^{\prime}$ distante... Você tem qualquer coisa a dizer a esse respeito?

ACS: Tanto quanto sei, em mim, no meu corpo, o outro está obsessivamente presente. Há, dentro de mim, amigos e inimigos. O Grupo Surrealista de Paris que foi, de certa maneira, exemplo de todos os outros, deixou histórias de lutas entre os surrealistas que o compunham. Aqui, com todas as dificuldades do regime político, alguns intitularam-se surrealistas (pessoas que, a meu ver, eram por demais próximas de um academismo que nos parecia insuportável, do qual sobressai António Costa). Assim, em 1949, sob a designação de "OS SURREALISTAS" fizemos a nossa primeira exposição tendo eu - o mais velho de todos - 29 anos. Como poderia o Surrealismo aqui ter começado mais cedo? 
Correspondo eu às suas perguntas? De maneira que direi novamente que não, nunca foi a minha razão ser um intelectual, mas sim um HOMEM ENTRE OS HOMENS. Como poderia ser de outra forma se não frequentei liceus, faculdades e academias?! Espero que os outros interpretem o que fiz. Cada traço, cada pincelada ou cada palavra escrita espera e deseja interpretação. A interpretação ou o "ensaísmo" são para mim a maior prova de "AMOR LOUCO" que exigia André Breton.

Licença: (우 (1) ()

Concepção e realização da entrevista:

Ana Cristina Joaquim

Pós-doutoranda na Universidade Estadual de Campinas. Doutora egressa do Programa de PósGraduação em Literatura Portuguesa da Universidade de São Paulo.

Contato: wiquen@gmail.com

(D) : https://orcid.org/0000-0002-7227-0195 